\title{
Arbor
}

\section{¿Jóvenes sin religión?}

\section{Javier Martínez Cortés}

Arbor CLXXI, 676 (Abril), 745-766 pp.

Se busca una aproximación a la religiosidad juvenil en el marco de situaciones socio-culturales más estables. La secularización implica una pérdida del monopolio religioso por parte de la Iglesia y serias dificultades para la socialización religiosa de las generaciones jóvenes. Los estudios muestran un núcleo (que disminuye en cantidad) de catolicismo practicante y una tendencia hacia la des-institucionalización en amplios grupos: formas privadas de de-construcción y reconstrucción de lo religioso (a-eclesialidad) o la simple indiferencia ante todo planteamiento religioso (a-religiosidad). Asimismo es posible detectar una cierta «búsqueda de iniciación" extramuros de la institución, y también en formas sociales de marginalidad. En un horizonte de futuro habría que contar con cambios de largo alcance en la sociedad europea (des-clericalización de la Iglesia) y mundial (globalización y defensa de los derechos humanos por parte de las religiones).

\section{Introducción}

«El barómetro juvenil marca siempre variable»-señaló en uno de sus escritos Joaquín García Roca- ${ }^{1}$. Por tanto, cualquier aproximación a la juventud como realidad estática está condenada a verse refutada por la móvil realidad de los jóvenes.

Pero además, en la sociedad contemporánea, heterogénea y pluralista, su «producto generacional» -el mundo de los jóvenes- es, lógicamente, también heterogéneo y plural.

No se puede hablar de «juventud" porque no hay una condición juvenil única, ni una realidad común para todos los jóvenes. Todo lo que nos 
puede parecer representativo de «la juventud» puede ser siempre negado por un grupo juvenil u otro.

Por tanto, la aproximación al mundo juvenil ha de ser necesariamente cautelosa. Especialmente en materia tan escurridiza como es la religiosidad.

Sin embargo, también creemos que bajo la móvil apariencia de la superficie, en ámbitos juveniles hay corrientes que fluyen en una determinada dirección, orientadas por los cambios de la sociedad global. Estas tendencias son las que nos permitirían romper las limitaciones de la mera sociografía religiosa y emitir algún tipo de hipótesis sociológicas plausibles.

¿Cuáles serían estos rasgos de la estructura social contemporánea, relevantes para la consideración del mundo religioso de los jóvenes? Ante todo, el que primero salta a los ojos, es el hecho de la secularización en las modernas sociedades occidentales.

\section{El afianzamiento de una cultura secular como «definidora de la realidad» en la sociedad española}

Es conocida la ambigüedad del término «secularización» y la multiplicidad de sentidos que puede abarcar y que de hecho ha abarcado en la investigación empírica. Hasta tal punto que se ha propuesto su eliminación y su sustitución por otro de contenido más preciso. Pero es precisamente esta capacidad multi-uso la que ha implantado el término (pese a su inicial carga ideológica).

Lo que habría que pedir a cambio de su uso es especificar, en cada caso, qué se quiere decir con él. Permítasenos, por tanto, utilizarlo una vez más.

Con él queremos aquí aludir al afianzamiento, de una «cultura secular» (es decir, una cultura orientada hacia «este mundo»), que va vertebrando la estructura de la España contemporánea, que disminuye el peso público de las instancias religiosas y que se impone en la vida cotidiana como componente cultural de evidencia inmediata, capaz de «definir la realidad" social (es decir, de establecer pautas de conducta socialmente legitimadas).

Esta cultura secular puede manifestar un respeto y un interés -variable- por las manifestaciones de lo religioso, que tratan de aludir a «otra» realidad. Pero se constituye como tal cultura con independencia del beneplácito de la religión. Aunque sea indudable en todo Occidente el influjo de los antecedentes religioso-cristianos la sociedad, como tal, se declara laica. 
Esta cultura laica alcanza grados crecientes de complejidad y extensión, a partir de 1975, en los procesos modernizadores de la sociedad española. La modernización significa el pluralismo religioso: una pérdida del monopolio ostentado históricamente por la Iglesia Católica. Sin embargo, el peso social hegemónico del catolicismo continúa presente. La Constitución española de 1978 lo reconoce con una mención explícita de la Iglesia. Así se compromete a «tener en cuenta las creencias religiosas de la sociedad española y mantener las consiguientes relaciones de cooperación con la Iglesia Católica y las demás confesiones» - art.16, parágr. 3-. Pero en la práctica la religión, en adelante, será un tema de elección personal.

Esta mutación del trasfondo jurídico-religioso de la sociedad española ha tenido silenciosas pero profundas repercusiones en los procesos de transmisión del catolicismo. El hilo de la tradición religiosa que unía a las distintas generaciones se mostró quebradizo ante los rápidos cambios.

Aún admitiendo una fuerte dosis de cautela ante los métodos cuantitativos en temas religiosos, los datos estadísticos apuntan en esta dirección. El manejo de la estadística corre siempre el peligro de ser engañoso -la estadística como la tercera forma de mentir-: pero más en asuntos religiosos. El instrumento utilizado es inevitablemente insuficiente para captar entre sus mallas esos peces sutiles que William James llamó «las variedades de la experiencia religiosa».

Con todo, no deja de ser razonable el argüir que la religión es un fenómeno colectivo, y que -especialmente en el caso del catolicismo- se vive entretejido en una serie de actos muy concretos. Lo cual implica que se preste con facilidad a una cierta cuantificación. Los números serán toscos, pero «algo» dicen. Lo importante sería, posteriormente, «agredir» a los números con hipótesis interpretativas de lo que significan en un contexto social determinado.

Pues bien, la primera Encuesta de la Juventud española -en 1960reveló que la juventud masculina (de la femenina no se preocuparon los encuestadores) se declaraba católica en una abrumadora proporción global («muy buen católico», «católico practicante» $\mathrm{y}$ «no muy practicante»): en total, un $91 \%$. El resto se resumía simplemente bajo el rótulo de «no practicante», sin mayor especificación.

Quince años después la Encuesta de la Juventud de 1975, comprendiendo ya varones y mujeres, reflejaba una pérdida importante en la práctica religiosa de los jóvenes españoles. Los practicantes (en cualquier grado) habían descendido casi 30 puntos -del 91 al 61,9\%-. Los «no practicantes» habían alcanzado más del $18 \%$ y una nueva categoría, los «in- 
diferentes», representaban el 19,7\%. Los «ateos» aún no existían metodológicamente.

Otros quince años después (en 1989) los jóvenes españoles se autocalifican como "practicantes» en un $40 \%$, «no practicantes» en un $20 \%$ y la suma de «indiferentes» $y$ «ateos» (ya aparecen en las encuestas) alcanza algo más del $38 \%{ }^{2}$.

¿Y hoy? El proceso de erosión de la práctica religiosa continúa. Según el estudio Jóvenes españoles 99, del tramo juvenil comprendido entre los 18 y los 24 años, sólo un $12 \%$ asiste a misa semanalmente. Ocho puntos menos de los que arrojaba el anterior estudio de la misma Fundación Santa María en $1994^{3}$.

¿Hay razones para sospechar que ha tocado fondo? ¿Y cómo interpretar esta erosión creciente, entre los jóvenes, de la práctica religiosa institucionalizada?

Sin duda, una pluralidad de causas está operando en el fenómeno (como en todo hecho social). Pero lo que los números denotan ante todo es una fractura creciente de la relación entre las generaciones más recientes y la institución eclesiástica.

\section{La relación jóvenes/institución religiosa}

En un país como España, en el que la religión ha sido monopolio de la Iglesia Católica, lo que los números indican en primer lugar es una poco satisfactoria relación entre jóvenes e Iglesia.

¿Y cómo es esta relación? Ante todo, asimétrica.

Frente al manifiesto interés de la Iglesia por establecer nuevos puentes de contacto y de mantener los ya existentes, la Iglesia como institución apenas suscita interés para una mayoría apreciable de los jóvenes. No habría que dejarse deslumbrar por las magnitudes cuantitativas -de la juventud mundial- que la figura carismática de Juan Pablo II es capaz de convocar en un lugar determinado y en muy determinadas ocasiones. Aunque el fenómeno es notable y estos números reconforten a los líderes institucionales, estos jóvenes no constituyen sino una minoría de sus respectivos países. Concretamente, en España, (de una muestra de más de 3.800 ) un 21\% confiesa: «Apenas he tenido relación con la Iglesia». Y para un $31 \%$, este contacto les ha dejado indiferente.

Preguntados acerca de la valoración que hacen de su contacto con instituciones católicas, un $40 \%$ de los encuestados declaran tener una impresión positiva, o muy positiva. (Negativa, o muy negativa, sólo un $7 \%$ ). Pero en conjunto, más de la mitad de los jóvenes parece no sentir interés 
por la institución a la que teóricamente -los bautizados hasta ahora son abrumadoramente mayoritarios- pertenecen. "No tengo necesidad de la Iglesia para creer en Dios» afirma un 71\% (lo cual sería una confesión de a-eclesialidad, de la que también participan jóvenes que se afirman creyentes). Comparados con la respuesta a este item en 1994 (un 76\%) incluso supone un cierto progreso en la conciencia de la necesidad de la Iglesia.

Tampoco parece que la institución religiosa les merezca gran confianza a la mayoría. Interrogados sobre el grado de confianza que tienen en diferentes instituciones, tan sólo un $29 \%$ afirma confiar mucho o bastante en la Iglesia. El primer puesto se lo lleva el sistema de enseñanza, con $63 \%$; el segundo, la Policía, con casi un 56\%; y el tercero es para la Prensa, con un $44 \%$.

Consecuentemente, la capacidad socializadora de la institución religiosa se ve muy disminuida. Incluso más de lo que los datos anteriores indicarían: no llega al 3\% el porcentaje de los jóvenes que señalan a la Iglesia a la hora de expresar dónde se dicen cosas importantes para orientarse en la vida.

Resumiendo: según el estudio Jóvenes españoles 99:

a) Existe un número que, por una variedad de motivos diferentes, rechaza a la Iglesia

b) Un número que va creciendo (actualmente supera la mitad de los encuestados) manifiesta una actitud de displicente ignorancia («apenas he tenido relación con la Iglesia»), o bien de absoluto desinterés («la dimensión religiosa no va con mi forma de ser»), o bien -y aquí habría también que incluir a jóvenes creyentes- piensan que «no tengo necesidad de la Iglesia para creer en Dios».

c) Y un $40 \%$ la aceptan, aunque no todos practican su fe. El «núcleo duro» de jóvenes católicos practicantes ha descendido en los últimos 5 años del $20 \%$ al $12 \%^{4}$. De los restantes cabe sospechar que un buen número de ellos ven a la Iglesia más como un espacio acogedor (son posmodernos) que como una instancia portadora de sentido último. "Me gustaba el ambiente que había» responde el 56\% de los que hacen una valoración positiva de su relación con la Iglesia.

Parece legítima la inferencia de que los procesos de socialización religiosa (durante el último medio siglo), incluso partiendo de unas generaciones que se declaraban masivamente católicas, han tropezado con serias dificultades. ¿Tal vez el cambio del contexto cultural con la modernización no ha sido adecuadamente considerado por la institución religiosa en los procesos catecumenales? 
Hoy, la consideración actual de estas dificultades viene a perfilar un panorama de incertidumbre en el futuro respecto a una parte considerable de la población española. Enumeremos someramente algunas de las dificultades más evidentes:

- Ante todo, la crisis religiosa de la familia, que a su vez es resultado de una variedad de factores. La ausencia de incipiente socialización religiosa de los hijos en la familia es el primer hueco (difícil de llenar más tarde, aunque sea posible). El papel de la familia es muy determinante en la transmisión de la fe religiosa: más aún que en la transmisión de la irreligión, pues ésta se da con más espontaneidad a través del ambiente reinante. Se ha podido formular la hipótesis de que allí donde se den unos padres con convicciones débiles (sean religiosas o irreligiosas), la actitud de los hijos se orientará -en ausencia de otros influjos religiosos posteriores- hacia el polo de la irreligiosidad.

- La «sociedad de la imagen» en la que el joven vive ineludiblemente inmerso, no ayuda a la socialización religiosa. Las magnitudes sociales, en una sociedad crecientemente compleja, suelen ser valoradas según una imagen global, lo que constituye el imaginario colectivo. Por una diversidad de causas, el hecho es que la imagen de la Iglesia, para un buen porcentaje de los jóvenes (como se deduce de los datos aportados) es sencillamente irrelevante. La «lectura» que de la Iglesia se hace en los medios de comunicación social no les ayuda a mejorar esta imagen.

- Los cambios demográficos en la estructura de los agentes de socialización religiosa tradicionales (clero, religiosas/us) abren una distancia cada vez mayor, pese a los esfuerzos y la buena voluntad, con respecto al plural mundo de los jóvenes. Estos tienden a tener una imagen estereotipada de la Iglesia difícil de romper por un clero envejecido. El relevo generacional del mismo resulta claramente insuficiente.

- Por otra parte, en una sociedad secularizada lo religioso tiende a ser considerado -y más en ámbitos juveniles- como un asunto puramente privado. Para un buen número de ellos, sus creencias y sus prácticas religiosas serán no tanto resultado de la socialización religiosa recibida, sino más bien de las propias elecciones personales, la llamada «religión a la carta», que responde a una cierta «lógica de mercado cultural».

Así se ha formulado la hipótesis (Javier Elzo, 1994) de una cierta aeclesialidad juvenil que no supone una renuncia a lo religioso. Daría ori- 
gen, más bien, a una reconstrucción individualizada de la dimensión religiosa. Reconstrucción que resulta muy desigual Se trataría de un proceso de apropiación de lo religioso como elemento vital, pero independientemente de lo que se considera «doctrina oficial» de la institución. No se aceptan sin más -como en otro tiempo- las ideas provenientes de la tradición cultural-católica. La plausibilidad de tales creencias es subjetivamente evaluada antes de incorporarla al acervo de las creencias propias (sin preocupación dominante de ortodoxia).

Esta reconstrucción supone, por tanto, una cierta deconstrucción previa de lo heredado (que puede ser muy escaso en ocasiones, por la crisis de la socialización religiosa inicial en el seno de la familia y la escasez de referentes religiosos en la sociedad secularizada).

En la nueva elaboración adquiriría un peso preponderante, no tanto el elemento intelectual, sino el experiencial/emocional. Este rasgo experiencial podría manifestarse en una doble vertiente: una más individualista y más comunitaria la otra, y por tanto más susceptible de control institucional.

a) La individualista ha sido denominada «religiosidad de ajuste existencial» 5 . Tendría como base alguna modalidad de oración individual (por regla general de petición) ante las dificultades de la vida. La experiencia religiosa aquí es de carácter muy individual, y no parece precisar de mediaciones comunitarias. Quien la hace no se siente necesariamente vinculado a ritos institucionales. La reconstrucción, a partir de la experiencia de «ajuste», puede tener grados variables de ortodoxia.

b) La «religiosidad de interdependencia» sería el nombre que designa la experiencia comunitaria, basada en la pertenencia a algún grupo de orientación religiosa. Si el grupo es cercano a la Iglesia -aunque se trate de grupos eclesialmente contestatarios- existe una vinculación indudable con la ortodoxia. La «tonalidad» del grupo, sin embargo, puede estar determinada por el compromiso ético o bien por la emocionalidad religiosa interiorizada y compartida. También hay una vinculación con la práctica católica que el grupo intenta vivir no rutinariamente -por ello tal vez se rechaza el comprenderla primariamente como «obligaciones impuestas»-. Es decir que, con un aire innovador, se produce una socialización católica a través del grupo comunitario.

Pero también, dentro de esta «religiosidad de interdependencia», habría que incluir los casos en los que el resultado no es una re-elaboración, sino una ruptura con el modelo de religiosidad recibida: así la incorporación a sectas contemporáneas o el paso -muy minoritario-a otras 
religiones -Islam, Budismo-. O la sintonía con alguno de los «nuevos movimientos religiosos» más difundidos -por ejemplo «New Age»- que carecen de estructuras organizadas.

Este pluralismo religioso real acompaña históricamente al establecimiento de las sociedades modernas, laicas y democráticas. La modernización española (históricamente tardía si se la compara con la de otras sociedades centroeuropeas) estaría diluyendo hoy las actitudes de la religiosidad tradicional y su vinculación con la institución eclesiástica. En conjunto, nos estaría aproximando a índices de religiosidad similares a la media europea.

Es evidente en toda Europa un cierto apagamiento generalizado de la fe cristiana y un descenso en la práctica cristiana (tanto en el aspecto cúltico-ritual como en el cumplimiento de normas morales). La religiosidad eclesiocéntrica ha perdido gran parte de su anterior fuerza gravitatoria. Paradójicamente en apariencia, Europa occidental se caracteriza por un cierto nivel de creencia en Dios, compaginado con otro nivel inferior de fe en lo trascendente. También la divinidad en la que creen puede perder progresivamente los rasgos del Dios cristiano, «Padre de Jesucristo», y adquirir los perfiles de una «fuerza cósmica». (Fundación EVSSG. Encuesta sobre el sistema europeo de valores. Amsterdam, 1992). De todo lo cual se pueden encontrar muestras entre los jóvenes españoles, muestras que incluso superan la media europea.

Consultemos los datos del Eurobarometer 32 (1992) y comparemos la media en Europa con los porcentajes que indica para la sociedad española: «Personas religiosas», un 65\% la media europea (España, un 68\%). «Agnósticos», un 4\% (España, un 6\%). «Ateos», un 6\% (España, un 7\%). «Personas no religiosas», un 20\% (España, un 14\%).

Es de notar que los resultados del Eurobarometer, para la totalidad de la población española, en el rubro "Personas no religiosas", son muy inferiores al porcentaje indicado por Jóvenes españoles 99. ¿Es una mera radicalización juvenil y pasajera, o significa un movimiento duradero de las jóvenes generaciones hacia la indiferencia religiosa?

Sería interesante poder dar una respuesta verificable a esta pregunta. Pero de momento no la tenemos, por falta de estudios transversales que sigan la evolución religiosa de una determinada generación.

En resumen, podemos agrupar en tres grandes vertientes las posiciones religiosas de los jóvenes españoles:

a) Las que marcan un suficiente acuerdo con las ideas e imágenes de Dios explicitadas en la tradición cristiana.

b) Las que adhieren a la idea de un «dios cósmico» impersonal (trasvase hacia otra religiosidad, de corte oriental). 
c) Las que se declaran exentas de cualquier forma de religiosidad. Bien porque niegan explícitamente a Dios (ateos), señalan carecer de motivos para creer en Él (agnósticos), o bien afirman «pasar del tema y no interesarse por él» (indiferentes).

En cualquier caso, se percibe un progresivo distanciamiento entre la institución religiosa y las generaciones jóvenes. La relación predominante, más que el enfrentamiento, sería la indiferencia. Un deslizamiento de jóvenes, cristianos nominales, hacia formas de vida en las que tanto las ideas como los sentimientos, los símbolos, los rituales celebrativos y las pertenencias tienden a no enraizarse eclesialmente. Hasta ahí no habríamos constatado sino la a-eclesialidad mayoritaria juvenil (con la excepción de núcleos que tienden a disminuir).

Esta a-eclesialidad unas veces desembocaría en la indiferencia religiosa y otras conduciría a una re-elaboración de la religión recibida.

Pero, incluso en caso de permanencia de actitudes religiosas, es innegable la tendencia hacia procesos de des-institucionalización de la experiencia religiosa.

\section{La des-institucionalización de lo religioso como fenómeno propio de las modernas sociedades occidentales}

¿Cabe formular alguna hipótesis explicativa del fenómeno?

J. Habermas, en su teoría comunicativa e inspirándose en E. Durkheim, sugiere que la situación cultural de las sociedades modernas, caracterizada claramente como de crisis (crisis de legitimación, crisis de identidad, crisis de motivación, etc.) vendría a ser causada, en último término, por lo que él llama «explicitación de los símbolos sagrados en lenguaje» (Versprachlichung des Sakralen).

Se trata de un intento más de explicar el «desencantamiento del mundo" (Weber) con el advenimiento de la Modernidad, y la pérdida del sentido, al menos como convicción generalizada. La retorcida denominación alude al hecho de que las funciones integradoras, que en las sociedades tradicionales se cumplían mediante la vivencia de los ritos, dotados de una significación sagrada, es decir, incuestionable (das Sakrale), ahora, en las sociedades modernas, deben ser realizadas mediante la «acción comunicativa», en la que una argumentación se expresa a través del lenguaje (Versprachlichung).

De la interacción, mediada simbólicamente, se pasaría a la interacción regulada por normas. El proceso lo explica Durkheim a través de la evolución del derecho, que va desde su cumplimiento ritual hasta el con- 
trato. Y consiste en que el consenso básico, de carácter religioso, expresado mediante símbolos rituales, se disuelve: las normas morales y políticas pierden su cobertura sacral, que las hacía indiscutidas. Pero el lenguaje intenta recuperar el carácter fundante de lo sacro, mediante la razón argumentativa. Trata de producir y mantener la cohesión social como «comunidad de comunicación»: es decir mediante un consenso razonado y logrado comunicativamente en la opinón pública.

Este proceso, voluntariamente aceptado por una mayoría, habría conducido a la constitución de las modernas sociedades democráticas y laicas. Y ha supuesto una socialización eficaz en esta acción comunicativa entre poder y ciudadanos.

En este tipo de sociedades, en el que la comunicación fundamenta la cohesión social, el ámbito de lo religioso se ve inevitablemente afectado. La institución representativa de lo sagrado no logrará ya el consenso básico religioso mediante la simple apelación a su carácter simbolizador de lo sagrado.

En la situación anterior, lo sacro-simbólico, con su simple presencia, lograba constituir el consenso básico. La identidad individual era una pura reproducción de la colectiva. El disidente que la cuestionara significaba una amenaza para el símbolo de lo sagrado, que estaba en la base de la cohesión social. En consecuencia, este sacro-simbólico (que según Durkheim representaba a la comunidad) era defendido mediante el recurso a la violencia (persecución de herejes, etc.).

No jugaba ningún papel la acción comunicativa, productora de la intersubjetividad mediante el diálogo de dos sujetos. En consecuencia, no surgía la pregunta individual por el sentido de la propia existencia, tal como se produce hoy en las sociedades modernas (y si surgía era reprimida).

Pero al crearse una zona de libertad de conciencia, se fluidifican los símbolos de lo sagrado y requieren una explicitación mediante el lenguaje. La nueva situación hace emerger, a la vez, una nueva carencia y una nueva capacidad en el individuo.

La carencia consiste en la necesidad de interrogarse por el sentido de la vida, que en la situación anterior no se producía, puesto que el sentido venía «dado» por la adhesión colectiva a lo sacro-simbólico.

La nueva capacidad estriba en que la respuesta a la interrogante implica siempre la presencia activa de sujetos, capaces de dialogar.

Esta apelación al diálogo altera el estatus que la institución religiosa poseía por su imagen sacra en la sociedad. La base de validez de esta imagen ha cambiado, en el sentido de que remite a la capacidad argumentativa del lenguaje (como sucede en todo consenso mediado comunicativamente). 
La institución religiosa se verá requerida a ejercer una acción comunicativa suficiente para consolidar el consenso religioso. Su anterior condición de símbolo sagrado, capaz de constituir por sí mismo la adhesión colectiva, comienza a ser sustituida socialmente por su imagen empírica.

En adelante se verá sometida a crítica, o simplemente a distanciamiento. El fiel tenderá a concebirse a sí mismo como sujeto de diálogo. La pertenencia religiosa presenta un nuevo requisito: la aceptación libre del individuo.

Cuando este nuevo requisito, que implica una acción comunicativa por parte de la institución, no se cumple satisfactoriamente (por las circunstancias que fueren) la religiosidad insatisfecha pone en marcha procesos de «religiosidad a-eclesial». Es decir, se produce la des-institucionalización de lo religioso.

Consecuencias de esta des-institucionalización serían las formas de «adhesión parcial» (unos contenidos religiosos se aceptan, pero otros no). Aparecen las formas de la llamada "religión a la carta»: es decir, formas de sincretismo según criterios subjetivos de lo que al individuo le resulta más plausible en el terreno de las creencias.

El estudio Jóvenes españoles 99 ofrece muestras significativas de esta adhesión parcial. Un 50\% de los encuestados afirma: «Soy miembro de la Iglesia Católica y pienso continuar siéndolo. Pero sólo un $28 \%$ (poco más de la mitad) declaran: «En general, estoy de acuerdo con las directrices de la jerarquía de la Iglesia».

La adhesión puede hacerse tan tenue que llega a manifestarse en la negación de la necesidad de la mediación institucional: «No tengo necesidad de la Iglesia para creer en Dios», jun $71 \%$ de los encuestados!

El dato no sólo traduce una insuficiente socialización católica, sino una perspectiva sociológica de futuro poco halagüeño. Se rechaza a la instancia mediadora de la iniciación religiosa como si la creencia en el Dios cristiano fuera un mero dato «natural».

Esta idea de la prescindibilidad de la institución, tan masivamente declarada, es un factor multiplicador de largo alcance, si la propia institución no logra alterar su relación con una gran parte de las generaciones jóvenes.

\section{5. ¿Qué ocurre con lo sagrado-simbólico?}

¿Y los contenidos previos de lo sacro-simbólico que eran controlados y administrados por la institución religiosa? ¿Significa esto su disolución práctica en la cultura secular, como pretendieron ciertos ilustrados? 
En algún lugar, Habermas (un contemporáneo partidario de la Mlustración) insinúa, haciendo referencia a Mead, un trasvase de lo sagrado al lenguaje. La forma lingüística nueva no es de por sí incompatible con los contenidos simbólicos anteriores. El contenido semántico puede fluctuar de una forma -el símbolo- a otra -el lenguaje-. Ambos son caminos que pretenden un entendimiento del mundo en cuanto totalidad. Se puede producir una fusión de las significaciones en la forma de un saber cultural.

La acción comunicativa viene a declararse heredera de la producción de sentido, que antes era función de lo sacro-simbólico, pero no vacía a éste de significado. En adelante, sin embargo, el saber sacral ha de saber combinarse con el profano: sólamente de esta manera la religión se convierte en una imagen del mundo con pretensión de totalidad ${ }^{6}$. Hay que notar que esta postura teórica no implica una actitud creyente por parte de Habermas.

En esta dirección, dentro del panorama filosófico español, Eugenio Trías supone un esfuerzo ilustrado por «pensar la religión». Su Lógica del límite (1990) le empuja a reconocer un límite de la razón, más allá del cual se tropieza con el «cerco hermético», del que tenemos noticias a través de las religiones. En La edad del espíritu (1994) se pregunta si es posible ir más allá del límite y hablar sobre ello de forma significativa. «Todo el mundo contemporáneo... bascula entre un racionalismo incapaz de abrirse a las raíces simbólicas del espíritu y una apertura simbólica que no permite, tampoco, trabar vínculos fecundos y efectivos con el universo de la razón».

Estas posiciones representan una inflexión de la mentalidad ilustrada. Para Trías, la religión es una «asignatura pendiente» de la razón ilustrada, una «sombra» creada por la razón imperante en Occidente desde la Ilustración.

La cultura, aunque se ha designado como depósito, no es algo «que se tiene», sino que se produce y se reproduce, tanto la religiosa como la ilustrada adversa. La tradición cultural tiene vigencia en la medida en que se actualiza críticamente. El uso de la tradición es a la vez su renovación.

Para la época cultural que designamos como Modernidad, la religión venía a ser un residuo del pasado. La institución religiosa, a lo sumo, perduraría en las zonas periféricas y poco ilustradas de la sociedad moderna. Así lo interpretaban ciertas versiones sociológicas extremas de la tesis de la secularización.

Pero, para su sorpresa, la historia concreta vino a falsar empíricamente la tesis secularizadora radical. La atmósfera cultural de la Posmodernidad altera las perspectivas del futuro previsto.

El «nuevo individuo» (el posmoderno, es decir el que constituye las nuevas generaciones) es alguien que ha perdido muchas de las esperanzas míticas que se depositaron sobre la razón moderna. El posmoderno 
desconfía de las visiones unitarias de la historia y de las «grandes palabras» (Libertad, Igualdad, Felicidad). No serían sino «metarrelatos» que cubren con su manto las contradicciones reales. Intelectualmente se conformará (reconoce que el pensamiento es «débil») con un mundo fragmentario, donde encontrar fragmentos de libertad, de igualdad, etc. ¿Y qué se hizo de la felicidad? Todo con minúscula. Las mayúsculas son producto de metarrelatos.

En este estado de ánimo, si algunos aspectos religiosos -que aluden a otras maneras de ver el mundo- le ayudan, o le serenan, ¿por qué no admitirlos? Por las venas de la Posmodernidad, surgida en una «sociedad del riesgo», circulan vagas representaciones (la nebulosa místico-esotérica) de un «destino individual», pero tranquilizadoras, escritas en alguna parte. ¿Acaso es competente para rechazarlas la razón moderna, que tan estrepitosos fracasos ha cosechado?

Se produce un nuevo «escenario» de lo social: un re-encantamiento del mundo. Contenidos de lo sacro anterior, desvinculados de su coherencia institucional, representaciones sagradas provenientes de otras culturas religiosas y supersticiones circulan flotantes por los intersticios sociales, disponibles para la apropiación individual. La sociedad posindustrial y de mercado («sociedad del riesgo») es apta para fomentar esta apropiación: el individuo experimenta la necesidad de ser salvado. «Se siente la vida como un terrible azar en el que el hombre depende de voluntades misteriosas, latentes, que operan según los más pueriles caprichos. (El hombre solo)... no es capaz de ofrecer resistencia al destino y busca en las prácticas supersticiosas los medios para sobornar esas voluntades ocultas... El alma supersticiosa es, en efecto, el can que busca un amo» ${ }^{7}$.

Así, contra las predicciones de la Modernidad ilustrada, lo sagrado no desaparece, sino que «estalla», con una eclosión inesperada, en el corazón mismo de las sociedades posmodernas, desarrolladas, tecnológicas y comunicativas.

Pero esta religiosidad no retornará sin más a las instituciones encargadas de controlarla. La religión se privatiza: es un elemento más de la interioridad del individuo, inmune a las pretensiones de control de las instituciones religiosas (el posmoderno desconfía de las instituciones). Lo sagrado reaparece exuberante, pero en estado "salvaje», al margen de controles racionales. Su aparición tiene algo de freudiano: el retorno de lo reprimido. No se tratará de «religión pensada». La Ilustración, una vez más desde Hegel, quedará «insatisfecha».

Surge la pregunta: la institución religiosa, que velaba hasta ahora por el esfuerzo racional de lo religioso (fides quaerens intellectum), ¿no está dotada para desarrollar una acción comunicativa más eficaz que fuera capaz de «ilustrar» este retorno caótico de lo sagrado? 


\section{El carácter iniciático de la acción comunicativa religiosa}

No es fácil, en concreto, responder a esta pregunta. Aunque sí lo sea, desde una perspectiva sociológica, el señalar carencias actuales. Porque la acción comunicativa religiosa, en el contexto contemporáneo de una cultura de lo sensible -sociedad del consumo y de la imagen-se hace más compleja.

No basta con querer utilizar la capacidad argumentativa de un lenguaje basado en la tradición religiosa. Hay una multiplicidad de códigos de lenguaje (técnico, científico, publicitario, sentimental, religioso...) que circulan por la sociedad. Son códigos que, para su aceptación, exigen algún tipo de evidencia empírica.

El lenguaje religioso de una acción verdaderamente comunicativa implica hoy la remisión a una experiencia interior. Tiene un componente iniciático (que es propio de toda religión: introducir prácticamente en un camino transformador del sujeto) que ejercería como «verificación sensible» de lo sacro religioso. Una socialización religiosa duradera no puede prescindir de este componente.

Pero aparentemente la sociedad tecnológica ha perdido, en general, este carácter iniciático: la única iniciación posible sería la de las modernas tecnologías. Las instituciones que se ocupaban de los ritos de transición de la juventud (familia, escuela, iglesia) han visto disminuido, en la aceleración del cambio social, gran parte de su crédito. Encuentran cada vez más dificultades para asegurar las etapas de maduración y de inserción social de sus miembros.

Los elementos iniciáticos de épocas pasadas se han depositado en las capas profundas de la cultura y pueden emerger de esa profundidad en formas nuevas e inesperadas.

La aparición de nuevos tipos de religiosidades, cósmicas o sectarias, importadas de otros ambientes, constituyen un signo de una cierta «nostalgia de iniciación» a un mundo diferente. Culturalmente pueden aparecer como elementos extraños; pero precisamente por ello, el nuevo adepto encuentra en parte satisfecha la nostalgia de iniciación aludida.

Pero en la sociedad contemporánea existen también otros aspectos iniciáticos, marginales al clima general. Porque si carecen de una simbólica social en la que expresarse, los procesos iniciáticos, o sus sucedáneos, se abren camino subrepticiamente hasta explotar, incluso de forma virulenta. Si se analizan ciertos testimonios de jóvenes, se comprueba que es posible aplicar el ciclo de las pruebas iniciáticas (preparación-ruptura con el mundo anterior-ingreso en el "mundo nuevo») a experiencias tan diversas como las bandas de barrio, los toxicómanos, los grupúsculos 
de «cabezas rapadas»... Incluso las sesiones de terapia de grupo participan de este esquema. Pero tal vez el ejemplo hoy más llamativo sea el de las «noches de alcohol, calle y ruido» en las que los adolescentes, cada vez en edades más tempranas, son «iniciados» en un mundo al que los adultos no tienen acceso.

En la mayor parte de estos casos, la «prueba iniciática» se concibe como un «atajo» para desembocar en el resultado apetecido. El objetivo de la presunta iniciación (la transformación de la propia persona y de sus relaciones, con los demás y con el mundo) se expresa más bien en términos de «transmutación»; cosa que evoca, antes que un proceso iniciático -en el que se respeta la maduración lenta y progresiva de la personalidad- un procedimiento de alquimia.

En el plano de lo religioso, ¿subrayan suficientemente las confesiones cristianas este carácter iniciático, del que algunos grupos juveniles dan muestras de estar sedientos? Aunque por supuesto, no toda la «masa de bautizados» será receptiva al proceso.

Es cierto que las posibles deficiencias iniciáticas no eliminan sin más el carácter sacro de la institución. Pero su fuerza simbólica para dar expresión a capas profundas del ser humano queda relativizada: la institución adquiere un aire de «exterioridad» al sujeto religioso y sus posiciones doctrinales un matiz de «imposición»

A este impacto relativizador se le añade otro (repetidamente señalado por P. Berger): la manifestación del pluralismo religioso en el seno de una misma sociedad (o producido por la difusión mundial de las redes comunicativas) relativiza también, en algún modo, a todas las religiones, al hacerles perder el control de un espacio cultural homogéneo, que les daba èl aspecto de ser un fenómeno «natural».

Esta relativización del carácter sacro de lo religioso tiende a difundirse en una cultura laica. Lo que permanezca de la institución religiosa concreta será su imagen empírica. En el caso de la Iglesia Católica: una organización clerical que administra lo religioso con escasa participación de sus fieles.

\section{7. ¿Un proceso de disolución parcial de la religiosidad en las generaciones venideras?}

Las sociedades occidentales contemporáneas están atravesadas por corrientes culturales contradictorias. No todo -ni mucho menos- es «nostalgia de iniciación» en las generaciones jóvenes. Hay una negación de lo sacro y una fuerte tendencia relativizadora de la institución religiosa. 
$\mathrm{Su}$ imagen estereotipada en el imaginario juvenil puede conducir -y de hecho conduce- a una sensación de recelo/rechazo de la Iglesia entre las nuevas generaciones.

No es difícil apuntar hacia aspectos sociales concretos que producen este recelo: La lejanía de la parroquia como espacio vital para la juventud, la ausencia de referentes vitales atractivos, la disociación entre religión del libro y sociedad del espectáculo, la escasez de información religiosa en los espacios juveniles, la difícil situación del papel de la mujer en la estructura eclesial, la irrelevancia (para los jóvenes) de algunas disputas internas a la Iglesia, el envejecimiento del clero, el foso entre la doctrina de la Iglesia en materia sexual y la práctica juvenil generalizada en dicho campo... (Javier Elzo, Jóvenes españoles 99).

Pero la forma más radical no sería la de simple recelo, sino la de rechazo, que se expresaría como la indiferencia ante todo planteamiento religioso. Esta «desaparición» de la dimensión religiosa aparece como una tendencia expansiva entre los jóvenes.

Hasta qué punto la falta de interés por lo religioso es un fenómeno duradero, es algo que hoy no se puede decir. Pero las respuestas juveniles son bastantes categóricas al respecto: Uno de cada tres jóvenes, aproximadamente, manifiesta que «la dimensión religiosa no va con mi forma de ser». Uno de cada cuatro asiente al item (formulado más ásperamente y con un vocabulario juvenil): "Yo paso de Dios. No me interesa el tema». Uno de cada tres afirma: «No sé si Dios existe o no, pero no tengo motivos para creer en Éll». Y uno de cada cinco toma decididamente una posición personal negativa: «Para mí, Dios no existe» (Jóvenes españoles 99).

La indiferencia religiosa juvenil aparece como una relativa novedad, acompañando a la acelerada evolución de la sociedad española global ¿Es tal vez el precio a pagar por la modernización social? Ya Max Weber llamó la atención sobre el «desencantamiento del mundo» como una consecuencia de la implacable racionalización de las sociedades modernas. La esfera de lo sagrado parece diluirse, ante el influjo corrosivo de una dominante racionalidad instrumental.

España, en un lapso relativamente corto de tiempo, ha pasado por una modernización económica y política, y estaría realizando ahora su «transición religiosa» (Díaz-Salazar). Lo religioso es una magnitud histórica de mayor «longitud de onda» (de evolución más lenta) que la política y la economía. La llegada de esta última transición sería hoy palpable en la evolución religiosa de las actitudes de la población juvenil.

Si bien la religiosidad no desaparece socialmente (y la inflexión cultural que llamamos posmodernidad ofrece evidencias empíricas de ello, en 
múltiples formas), también es cierto que se está produciendo una «emigración» espiritual de los jóvenes fuera del área de lo religioso-divino (y no sólo de la tradición católica). Esta «emigración», ¿hacia donde va?

Los puntos de llegada pueden ser diversos:

a) Formas reflexivas de agnosticismo a ateísmo.

b) Un laicismo agnóstico no reflexivo. El mundo de lo empírico -especialmente en las sociedades de consumo- se bastaría a sí mismo. (Indiferencia religiosa, abundante, y con tendencia expansiva).

c) Aspectos de religiosidades no-teístas: formas de sacralización de realidades profanas. Podrían considerarse formas semi-ateas de religiosidad $^{8}$. Y vendrían a tener el formato de «religiones laicas de salvación». No es difícil encontrar ejemplos en la sociedad contemporánea. Gil Calvo las clasifica en «religiones políticas» (que se orientan hacia el grupo: nacionalismo, terrorismo, cualquier forma de mesianismo) y. «religiones narcisistas» (que tienen como objeto la propia individualidad, bajo aspectos diversos de «culto»: al dinero, al trabajo, al deporte.... $)^{9}$.

Esta que podríamos llamar «de-sacralización de la vida» no se puede atribuir ya simplemente a las posibles deficiencias de una acción comunicativa adecuada por parte de la institución religiosa. Se tiene que alimentar de fuentes diferentes.

Porque la acción comunicativa, para su posibilidad, requiere que ambos sujetos estén dispuestos a mantener un diálogo. Pero aquí una de las partes -la población juvenil ajena a cualquier planteamiento religioso- hace tiempo que dejó de tener interés en este diálogo. Viven ya en una zona cultural aparentemente blindada contra la idea de trascendencia. Sus actitudes funcionan con otra lógica social, a la que lo religioso le es ajeno.

Sin embargo, tal vez la institución religiosa no ha medido adecuadamente las posibilidades de contacto con los jóvenes que ofrecen hoy las redes modernas de comunicación. Tales posibilidades son atronadoramente explotadas por «lógicas» sociales propias de la sociedad de consumo. La publicidad de imagen y sonido ofrece a los jóvenes un interés mucho más cercano y más penetrante.

Porque en la sociedad contemporánea se producen ofertas competitivas de «lógicas» sociales diversas, a la búsqueda de clientela, y que traducen concepciones de valores vitales divergentes. Esta divergencia se formula por medio de «articulaciones simbólicas» diferentes.

Hoy, una de estas lógicas (la inmanente) absorbe la mayor parte del espacio vital de los jóvenes, en perjuicio de la otra (la religiosa/trascendente). En esta zona de inmanencia y de exacerbación sensorial se sitúa la indiferencia juvenil. 


\section{Las articulaciones simbólicas de la cultura en una moderna sociedad pluralista}

Entendemos por «articulaciones simbólicas» aquellas vinculaciones simbólicas entre códigos de conductas, en torno a las cuales se organiza el sistema de valores de un grupo. Socialmente establecen pautas de conducta últimamente coherentes, porque los valores que expresan tienen un marco de referencia simbólica común.

Las articulaciones simbólicas constituyen una prueba de que el lenguaje es capaz de fluidificar los símbolos, pero no disolverlos en su totalidad. El ser humano continúa siendo un «animal simbólico», aunque más complejo.

La observación muestra que el marco de referencia de las actitudes vitales suele expresarse en una combinatoria simbólica con los elementos espacio/cuerpo. Ellos permiten construir modelos de «articulación del sentido" de tipo opuesto, que orientan las conductas, puesto que alteran la estructura motivacional del sujeto. De este modo son capaces de integrar socialmente al individuo en alguno de los grupos propios de una sociedad pluralista.

a) En uno de estos modelos funcionaría una lógica que podemos llamar «promocional», propia de las modernas sociedades tecnológicas y de consumo. En el otro modelo se trata de una lógica de «ejemplaridad» y de «insularización», que viene de épocas anteriores (de sociedades más tradicionales en las que la religión era la principal fuerza vertebradora).

¿Cómo se articula ésta que llamamos «lógica promocional»? En torno a un eje simbólico horizontal, definido por la oposición «incompleto/completo». Con él tratan de expresarse los valores de la autorrealización personal, que aparece como definición última de la realidad individual. El «ser humano» nace en situación de carencias («incompleto») y a lo largo de su existencia ha de buscar su promoción hacia su «ser completo» (autorrealización).

Esta «lógica social», acusadamente individualista, es un producto de la sociedad liberal. Y, por tanto, es obvio que ha de encontrar un eco en sus ciudadanos. Pero al ser formulada simbólicamente, admite más de una posibilidad de concebir lo que se entiende por «autorrealización».

Con una mayor amplitud histórica se podría decir que la lógica de autorrealización es simplemente una lógica humanista. ¿Fue liberal, en sentido moderno, el Renacimiento? El eje horizontal (completo/incompleto) no excluye en principio el que una apertura a la trascendencia fuera la coronación de la autorrealización.

Sin embargo esta lógica, hoy, cabalga sobre el desarrollo de las posibilidades tecnológicas, de la imagen y del consumo de las modernas so- 


\section{¿Jóvenes sin religión?}

ciedades occidentales. El «ser completo» del hombre se exterioriza: implica una serie de prótesis tecnológicas (¿un joven puede considerarse «completo» sin teléfono móvil?), y un acceso a cierto nivel satisfactorio de consumo. Además, debería ser completado por una imagen satisfactoria de su cuerpo (que prima, colectivamente, sobre la imagen satisfactoria de la mente).

Esto es así porque el desarrollo tecnológico de imagen y sonido son eficaces promotores de una «cultura de lo sensorial». Es conocida la distinción -más compleja- que hizo Pitirim Sorokin entre «culturas ideacionales» y «culturas sensoriales». Una cultura ideacional es aquella en la que se juzga que para llegar a un «conocimiento verdadero» de la realidad es necesaria la confrontación de las ideas. En contraste con ella, una «cultura sensorial» juzga que el conocimiento de la realidad sólo se logra mediante el conocimiento de lo concreto: al cual se accede a través de los sentidos.

Entiéndase que se trata de un planteamiento no estrictamente epistemológico, sino sociológico: según el patrón cognoscitivo fundamental con el que los actores sociales organizan las pautas de su conducta. En el caso de una "cultura de lo sensorial», la consecuencia es que las sensaciones que afectan a los sentidos se convierten en la herramienta primordial que organiza los comportamientos. Las ideas parecen perder «sustancia de realidad».

El mundo adolescente y la «primera» juventud son especialmente sensibles a esta cultura sensorial. Las «meras ideas» no serán capaces de prevalecer en una posible confrontación con el mundo de las sensaciones, tan potentes e invasoras como las promovidas por la imagen y el sonido de la publicidad contemporánea. «El movimiento de las imágenes, los colores, la música, son lo suficientemente sugerentes como para que el resto de la realidad quede difuminado para el niño» ${ }^{10}$. (Y para el adolescente, e incluso para el joven).

Para vivir sólo basta con mirar, con lo que la lógica promocional del «hombre completo» queda mutilada. No importa, puesto que funciona como una coartada en la moderna sociedad de consumo. Se busca además que todo sea fácil, sencillo y divertido. La duda, la complejidad, la reflexión ya no serán necesarias. Todo queda respondido con la contundencia de las imágenes. Se deja de pensar para, básicamente, sentir. Y los sentimientos pueden también no ser muy permanentes, puesto que las imágenes (dramáticas o confortables) se superponen.

b) Frente a la potencia de esta cultura de lo sensorial, orientada ante todo hacia lo inmanente, el catolicismo (que en su época barroca cultivó los sentidos orientados hacia lo trascendente) ofrece hoy una cultura bá- 
sicamente «ideacional», con un lento desplazamiento hacia los medios de comunicación. La pugna con la oferta contraria se puede mantener en la sociedad de los adultos. Pero en el mundo de los adolescentes y de los jóvenes, blindado por las sensaciones inmediatas de su «hoy» y su inmanencia, parece sociológicamente problemática.

$\mathrm{La}$ «lógica social» alternativa que la institución religiosa ofrece la hemos designado como de «ejemplaridad» y está orientada por un eje simbólico vertical «alto/bajo» que implica una escisión en el hombre (lo que antropológicamente parece mejor fundado que la simple lógica promocional: el hombre es un animal escindido por contradicciones interiores). Pero los problemas surgen a la hora de designar en concreto dónde está lo «alto» y dónde lo «bajo»: de la sociedad y del individuo (el hombre es, también, un animal confuso).

Esta «lógica social» que la institución religiosa ofrecería como «ejemplar» la hemos también denominado de «insularización»: en el oleaje de imágenes de la cultura sensorial aparece con un (relativo) aislamiento. Ocupada en problemas internos, de identidad propia, no parece haber sido capaz, en una sociedad secular, de elaborar un lenguaje inteligible para las demandas plurales del mundo juvenil. (Es evidente que no todas éstas se sitúan en un plano religiosamente admisible). Pero, ¿qué demandarían hoy los jóvenes (algunos)?

En la literatura socio-religiosa no suelen faltar listas de estas demandas. Que, por cierto, no suelen estar formuladas por los mismos jóvenes. ¿Unas demandas imaginadas por adultos? He aquí algunas: una fe más experiencial, que supere el positivismo de «lo dado» (vías de iniciación a la oración) y que permita la exploración del «yo»; una «cultura eclesial» más democrática; mayor creatividad y más participación.

Probablemente es injusta la sospecha de que todo esto falta en la institución religiosa. Pero los datos que poseemos indican que así aparece en el imaginario de considerables colectivos juveniles. Y la identidad de éstos -una identidad inestable, compleja y «abierta»- se va construyendo sobre tres pilares fundamentales: la imagen que los jóvenes se van formando de sí mismos, la representación que de su entorno social se hacen (donde la Iglesia aparece con rasgos cada vez más borrosos) y el proyecto vital que ellos se trazan.

Si la institución religiosa logra mantener, con el contacto, una imagen positiva, y llegar a formar parte integrante del proyecto del joven, éste desarrollará una identidad católica. Pero los indicios van en la dirección de que tales contactos escasean.

Si el contacto no se produce, o es superficial o negativo, las aguas de la «cultura sensorial»e inmanente anegarán en muchos (los porcentajes 
tienden a crecer) el germen de religiosidad que, antropológicamente, se les puede atribuir. La lógica social de «ejemplaridad» que la institución religiosa pretende deja de funcionar para crecientes colectivos juveniles, instalados en la indiferencia.

\section{Conclusión: ¿Un futuro religioso de minorías juveniles?}

¿Se puede estimar que el futuro de la religión (implícito en estas reflexiones sobre los distintos grupos juveniles) está siendo subjetivamente problematizado por la mirada del espectador?

La primera observación sería que el espectador sólo observa el presente (no el futuro). Aunque dentro del presente ensaye el detectar ciertas tendencias.

La segunda observación es que tales tendencias dependen de ciertos factores, algunos de los cuales dibujan en el horizonte un «escenario» diferente.

Uno de los elementos decisivos sería el cambio en los sujetos de las relaciones sociales. La Sociología analiza procesos. Pero estos procesos tienen a sujetos como protagonistas. No nos parece defendible la concepción de una "sociología sin sujeto». ¿Pueden cambiar en este caso los sujetos de la relación Iglesia/jóvenes? no nos referimos a un cambio «moral», sino a un cambio situacional.

Entendemos que sí. Aparecen «escenarios» diferentes, resultado de un cambio social ya en marcha.

Uno de ellos, interno a la institución religiosa, que puede alterar su actual relación con la sociedad civil: la Iglesia Católica europea se apoya hoy sustancialmente en un clero envejecido y escaso. La imposibilidad de mantener la presencia social de la institución con estos recursos humanos se hace cada vez más evidente. Ello forzará (ya está ocurriendo, con legitimaciones teológicas incluidas) a la participación real y creciente de los laicos en la toma de decisiones. El «rostro humano» de la Iglesia Católica se va a configurar en un futuro cercano con un perfil diferente, probablemente menos lejano a la sociedad civil, y a los jóvenes.

Otro cambio ya en marcha, externo a la institución religiosa, puede afectar a la relevancia social de la Iglesia Católica (y también a las religiones en general). Nos referimos a la serie de confusos procesos que se subsumen bajo el término de «globalización». Si las religiones se erigen, decididamente, en defensoras efectivas de la dignidad y de los derechos de la persona, el proceso las acercará en una especie de «ecumenismo activo» y las abrirá hacia un panorama de relevancia mundial (relevancia que no excluye situaciones de abierta conflictividad). 
No parece temerario el inferir que la cifra «Dios» aparezca bajo una luz diferente en la sociedad europea (que es la que culturalmente, por proximidad, nos permitiría la inferencia). Y que esta luz, que resalta el perfil de la religión, tenga acceso al imaginario de los distintos grupos de jóvenes -también los españoles-, hoy distantes y recelosos.

Más allá de esto, la sociología sólo puede hacer una humilde -pero realista- declaración de incompetencia.

\section{Notas}

1 J. GARCíA RocA, Constelaciones de los jóvenes, Cristianisme i Justìcia, Barcelona 1994, p. 6.

${ }^{2}$ Fundación Santa María, Religión y Sociedad en la España de los 90, Ed. SM, Madrid 1992.

${ }^{3}$ En adelante, los datos cuantitativos que se indiquen a propósito de los jóvenes tienen como fuente el extenso estudio de la Fundación Santa María, Jóvenes españoles 99, Ed. SM, Madrid 1999.

4 Véanse los estudios de la Fundación Santa María de 1994 y 1999.

5 A. ToRnos y R. APARICIO, ¿Quién es creyente en España hoy?, PPC. Madrid 1995.

6 Véase, a propósito de esta cuestión, el artículo de G. AMENGUAL, "Acción comunicativa y cultura en la teoría de J. Habermas», en La comunicación, Publicaciones de la U.P. Comillas, Madrid, 1991.

7 J. ORTEGA y GASSET, El tema de nuestro tiempo, Espasa-Calpe, Madrid 1959, p. 139.

8 Cfr. R. DíAz-SALAZAR, "La religión vacía» en AA.VV., Formas modernas de religión, Alianza Universidad, Madrid 1994.

9 E. GIL CALVO, "Religiones laicas de salvación», en Formas modernas de religión.

10 BazARRA; CASANOva; García UGARTE: «Adolescentes, TV e Internet: ¿protagonistas o espectadores de la realidad?», Documentación Social, 124, Jóvenes del s. XXI. Madrid (julio-septiembre 2001). 